\title{
High gain 5G MIMO antenna for mobile base station
}

\author{
Yusnita Rahayu ${ }^{1}$, Indah Permata $\mathrm{Sari}^{2}$, Dara Incam Ramadhan ${ }^{3}$, Razali Ngah ${ }^{4}$ \\ 1,2,3 Faculty of Engineering, Department of Electrical Engineering, Universitas Riau, Indonesia \\ ${ }^{4}$ Wireless Communication Centre, Faculty of Electrical Engineering, Universiti Teknologi Malaysia, Malaysia
}

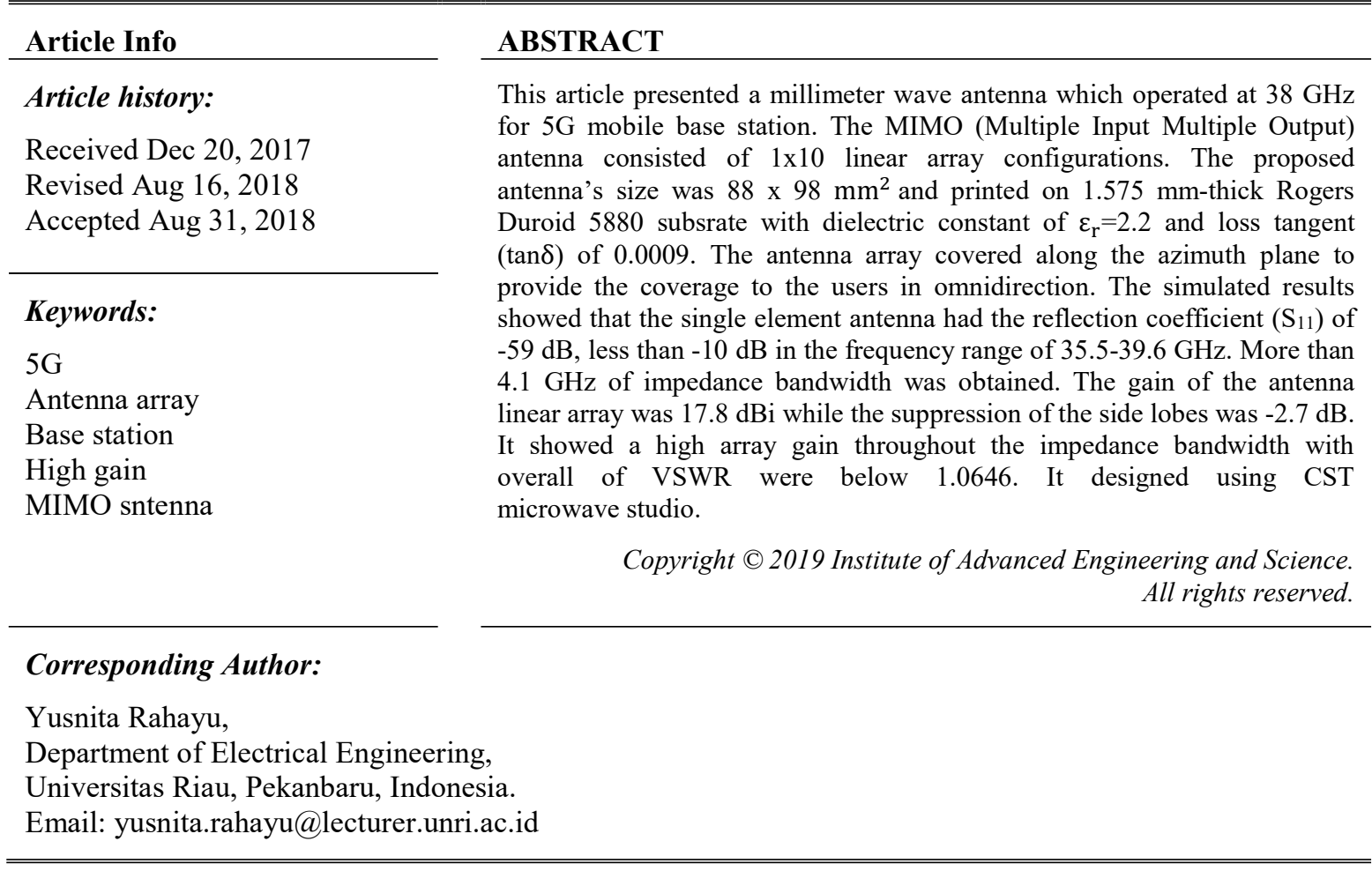

\section{INTRODUCTION}

The fifth generation $(5 \mathrm{G})$ mobile technology has been introduced and expected to be deployed in year 2020 [1]. In order to meet the fast growing wireless data capacity demands due to increasing users of smartphones, high growth in web and streaming, 5G technology now are highly given attention and undergo a huge research [2]. The 5G technology comes to solve problems and needs to improve network efficiency and capacity, improved data rates with better coverage at lower power consumption. Future 5G wireless systems have to satisfy three main requirements: i) having a high throughput; ii) simultaneously serving many users; and iii) having less energy consumption [3]. In the 5G era, lots of things such as electronic devices, vehicles and the equipment in the offices and homes will be wirelessly connected through the Internet. Users will be able to access ultra-high-definition (UHD) multimedia streaming and services such as Virtual Reality (VR) and Augmented Reality (AR) [4]. Untill now 5G standards are not available for us. However, some researches have started to put the base or the technology that will provide these standards. This technology mostly consists of wireless access systems, frequency utilization, power consumption, antenna and propagation [5].

The demand for higher quality and data rate was growing fast in the past few years. One of the most promising solutions to this problem is Multiple Input Multiple Output (MIMO) system. The MIMO technology made a great breakthrough by satisfying the demand of higher quality mobile communication services without using any additional radio resources and it has a significant ability to increase data throughput without additional bandwidth or transmit power (transmitter power). One type of antenna that can be used to increase the channel capacity of MIMO is a microstrip antenna [6]. The microstrip antenna has many benefits such as low cost, low profile, ease fabrication, and compact [7]. 
Massive MIMO technology and millimeter wave (mm Wave) communication has been considered as a key technology for the fifth generation wireless communication [8]. Mm-wave generally corresponds to 30-300 GHz frequency bands, but sometimes 10-30 GHz frequency bands are also included as they share some similar propagation characteristic [9]. Some of the candidate bands or $5 \mathrm{G}$ communications in the frequency of 20-50 GHz are specified in Figure 1. [10].

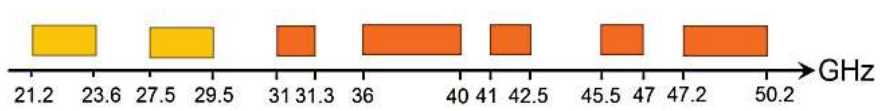

Figure 1. The candidate bands for the future $5 \mathrm{G}$ system in 20-50 GHz [10]

For mm-wave applications, problems to be concerned are the higher transmission loss and link stability, which could be overcome by increasing the gain and adopting the adaptive directional beam [4]. Massive MIMO base station is a promising technique for improving the capacity and service quality by accurately concentrating the transmitted energy to the mobile users [11]-[12]. Massive MIMO or large antenna array system has the capability of greatly improving spectral efficiency, energy efficiency, and system robustness [13]-[14]. In a typical massive MIMO system, single antenna mobile stations (MSs) communicate with a base station (BS) equipped with a large number of antennas [15].

The combination of mmWave and massive MIMO has the potential to dramatically improve wireless access and throughput performance such system benefit from large available signal bandwidth and small antenna form factor. the system also have advantages in terms of compact dimensions, energy efficiency, flexibility, and adaptivity that would make them ideally suited for 5G communication system [16]-[19]. In this paper, we proposed a high gain linear array 1x10 MIMO antenna which is used in 5G mobile base station operating at $38 \mathrm{GHz}$. The antenna has broad bandwidth with nearly omni directional pattern. The gain reached more than $17 \mathrm{dBi}$. This gain is relative high for omnidirectional pattern and broadband antenna.

\section{RESEARCH METHOD}

In this section, four (4) linear array configurations antennas, single element; $1 \times 6$ elements; $1 \times 8$ elements; and 1x10 elements will be described. First, single element antenna is designed to meet the desired requirement such as frequency $(38 \mathrm{GHz})$ and return loss. Then, this single element is used to form the MIMO configurations, $1 \times 6$ elements, $1 \times 8$ elements and $1 \times 10$ elements.

\subsection{Single element antenna}

The substrate selection is the first step in the designing of patch antenna. This paper uses RT Duroid 5880 as a substrate of the proposed antenna. The substrate parameters are summarized in Table 1. The geometry of single element antenna is shown in Figure 2 and the dimensions are summarized in Table 2.

Table 1. RT Duroid 5880 Parameters

\begin{tabular}{ll}
\hline Parameters & Value \\
\hline Dielectric constant $\left(\varepsilon_{r}\right)$ & 2.2 \\
Substrate thickness $(\mathrm{h})$ & $1.575 \mathrm{~mm}$ \\
Loss tangent $(\delta)$ & 0.0009 \\
\hline
\end{tabular}

Table 2. Single Element Antenna Parameters

\begin{tabular}{cc}
\hline Parameters & Value $(\mathrm{mm})$ \\
\hline W & 8.8 \\
L & 9.8 \\
H & 1.575 \\
Wf & 2.4 \\
Lf & 4 \\
Wp1 & 1 \\
Lp1 & 1 \\
Wp2 & 1 \\
Lp2 & 2 \\
Wp3 & 1 \\
Lp3 & 0.5 \\
Lp4 & 1.5 \\
\hline
\end{tabular}




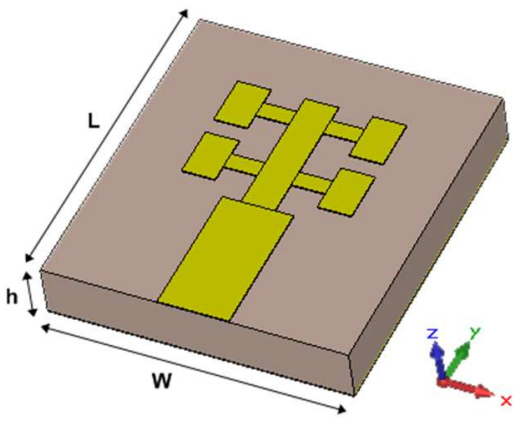

(a)

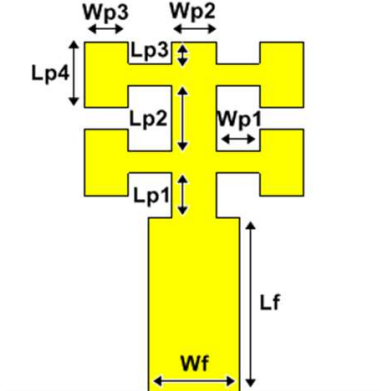

(b)

Figure 2. The geometry of single element antenna design, (a) 3D view, (b) top layer

\section{RESULTS AND ANALYSIS}

\subsection{Single element}

The significant importance in antenna design is the reflection coefficient $\left(\mathrm{S}_{11}\right)$ that defines the bandwidth and the impedance matching characteristic. The simulated result of the return loss for single element antenna is depicted in Figure 3.

The simulated results show that the single element antenna has the reflection coefficient $\left(\mathrm{S}_{11}\right)$ of -59 $\mathrm{dB}$, less than $-10 \mathrm{~dB}$ in the frequency range of 35.5-39.6 GHz. More than $4.1 \mathrm{GHz}$ of impedance bandwidth is obtained. Another imperative parameter beside the reflection coefficient and input impedance, that reflects the antenna performance, is the VSWR (Voltage Standing Wave Ratio), the antenna only can be able to operate at frequencies where the values of VSWR are inferior to 2 [20]. From Figure 4, we can see that the VSWR value is less than 2 .

The $2 \mathrm{D}$ and $3 \mathrm{D}$ simulated radiation pattern of the antenna design are presented in Figure 5. The radiation pattern of single element antenna provides gain of $7.66 \mathrm{dBi}$ with side lobe level is $-2.1 \mathrm{~dB}$. Total efficiency is $-0.978 \mathrm{~dB}$.

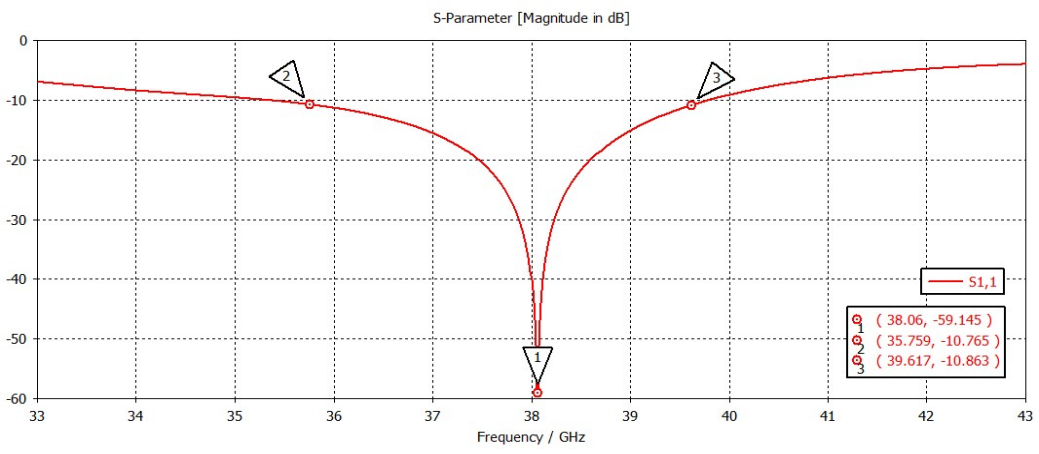

Figure 3. Simulated reflection coefficient $\left(\mathrm{S}_{11}\right)$ characteristics of the single element antenna

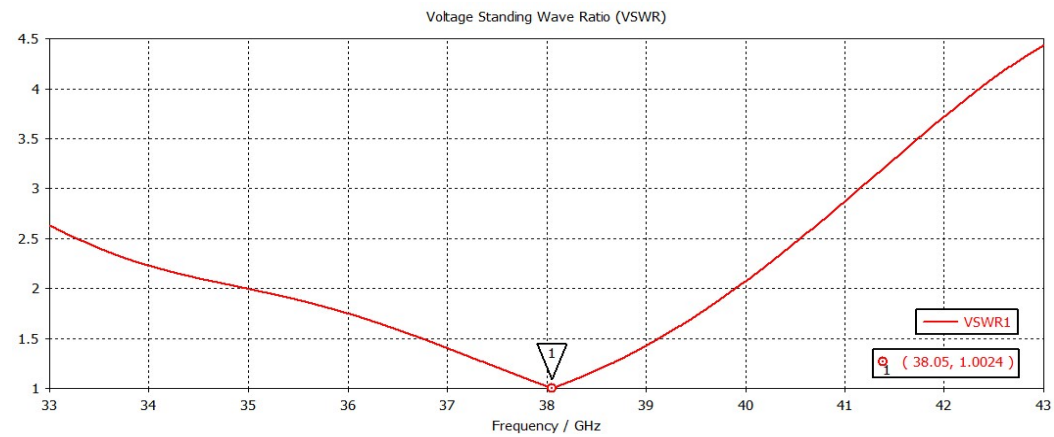

Figure 4. VSWR value of the single element antenna 


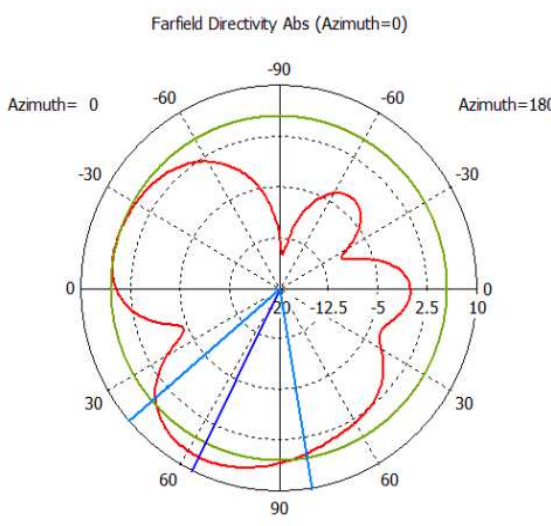

Elevation / Degree vs. dB

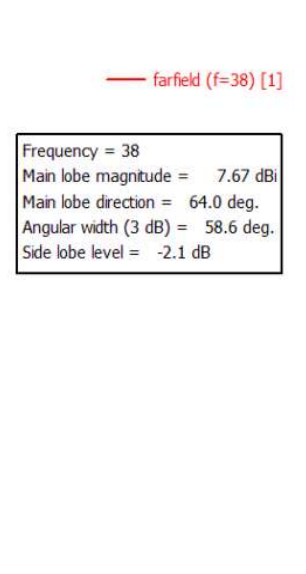

(a)

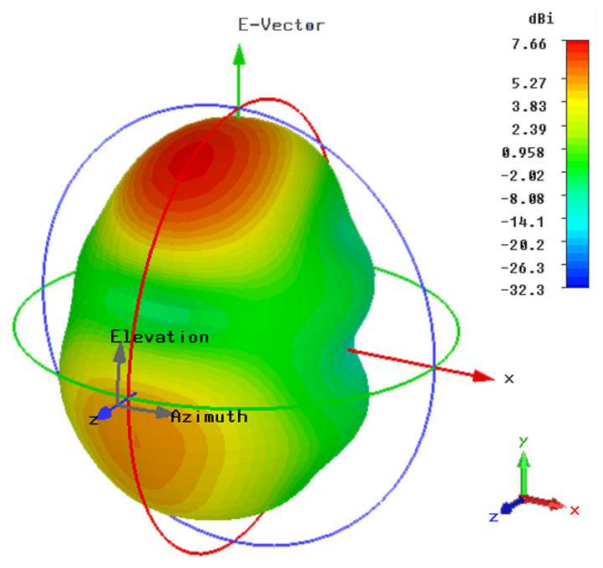

(b)

Figure 5. Radiation pattern of the single element antenna, (a) 2D model, (b) 3D model

\subsection{MIMO $1 \times 6$ elements}

The Figure 6 shows the design of MIMO antenna with six element antenna. The simulated radiation patterns are presented in Figure 7. It was observed when elements were assembled in the form of six element antenna linear array, there was an increase in antenna gain from $7.66 \mathrm{dBi}$ to $15.6 \mathrm{dBi}$ with side lobe level is $-2.8 \mathrm{~dB}$. Total efficiency antenna is $-1.371 \mathrm{~dB}$. Simulated S-parameters of the arrays are illustrated in Figure 8, the isolations between the consecutive ports, S21, S32, S43 etc., are well below -20dB which show a lesser mutual coupling between them.

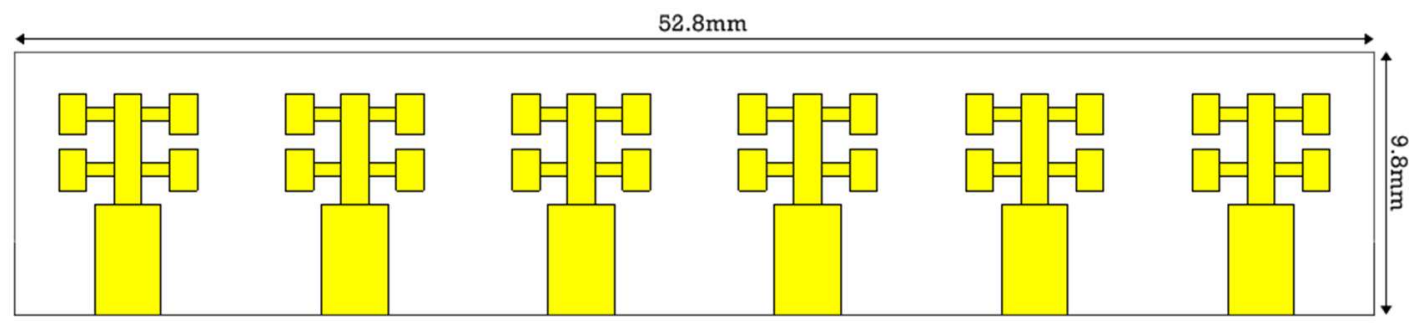

Figure 6. The geometry of six element MIMO antenna design

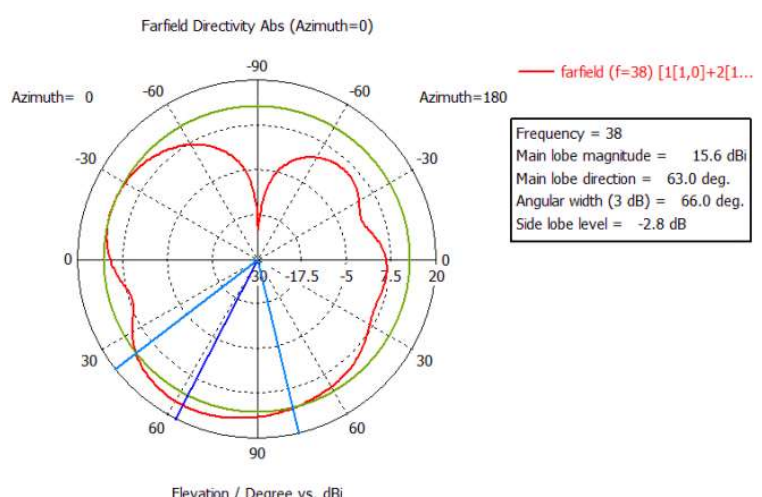

(a)

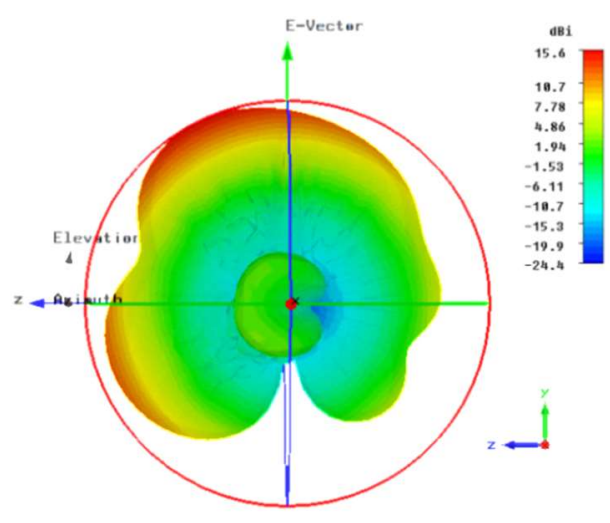

(b)

Figure 7. Radiation pattern of six element antenna, (a) 2D model, (b) 3D model 


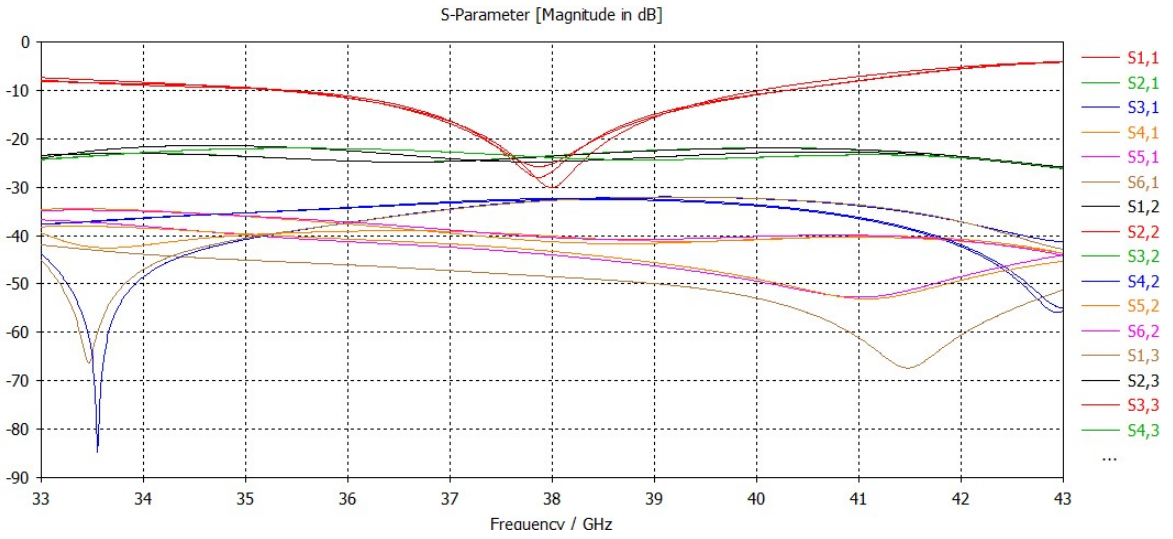

Figure 8. Simulated reflection coefficient $\left(\mathrm{S}_{11}\right)$ characteristics of $1 \times 6$ element antenna

\subsection{MIMO 1x6 elements}

The Figure 9 shows the design of MIMO antenna with eight element antenna. The 2D and 3D simulated radiation pattern are presented in Figure 10. There was an increase in antenna gain from $15.6 \mathrm{dBi}$ to $16.8 \mathrm{dBi}$ with side lobe level is $-2.7 \mathrm{~dB}$. Total efficiency antenna is $-1.393 \mathrm{~dB}$. Simulated S-parameters of the arrays are illustrated in Figure 11, the isolations between the consecutive ports, S21, S32, S43 etc., are well below $-20 \mathrm{~dB}$ which show a lesser mutual coupling between them.

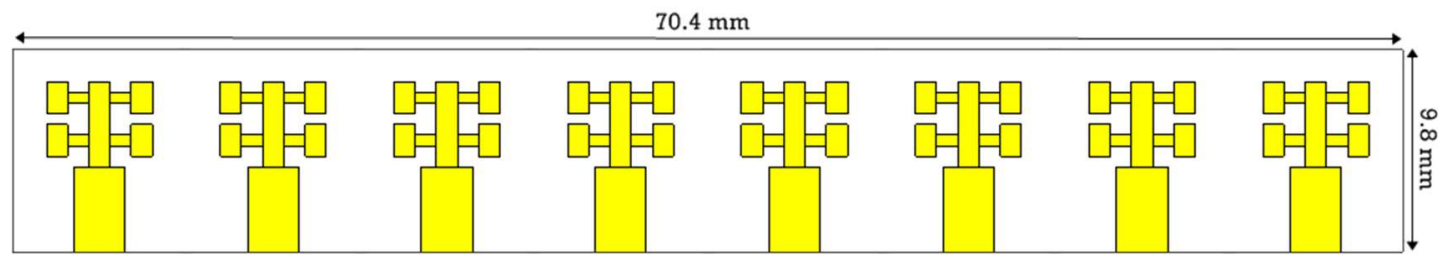

Figure 9. The geometry of eight element MIMO antenna design

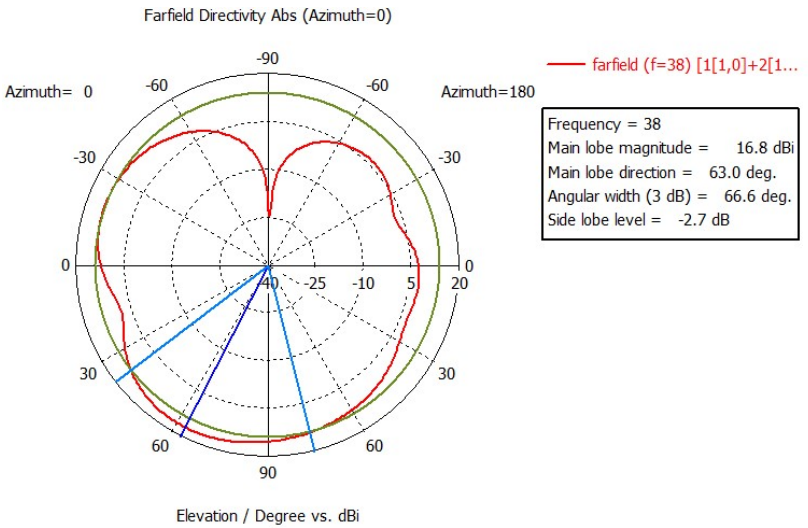

(a)

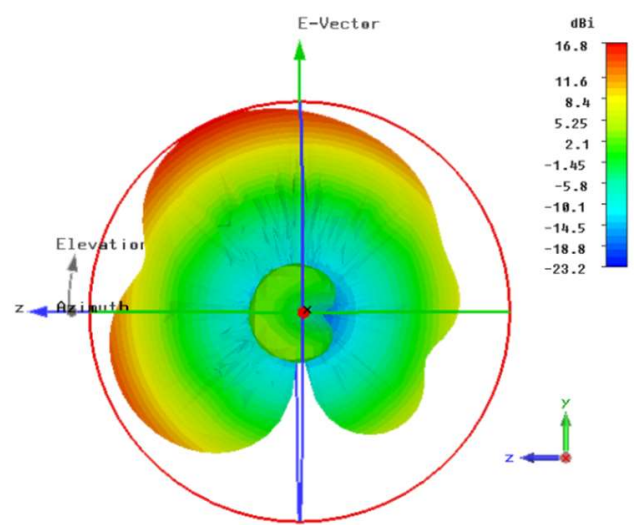

(b)

Figure 10. Radiation pattern of the eight element antenna, (a) 2D model, (b) 3D model 


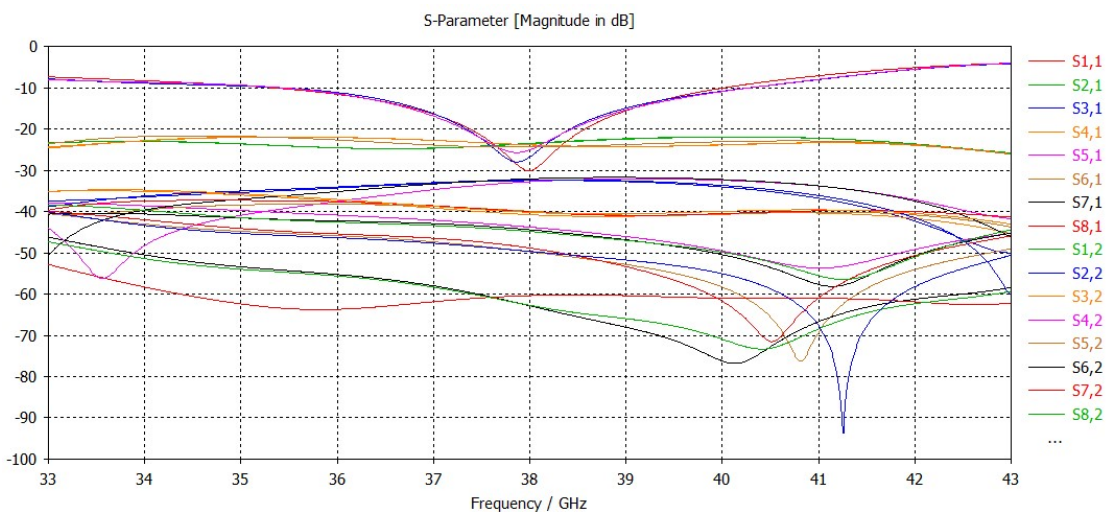

Figure 11. Simulated reflection coefficient $\left(S_{11}\right)$ characteristics of $1 \times 8$ element antenna

\subsection{MIMO $1 \times 10$ elements}

The Figure 12 show the design of MIMO antenna with ten element antenna. The 2D and 3D simulated radiation pattern are presented in Figure 13. There was an increase in antenna gain from $16.8 \mathrm{dBi}$ to $17.8 \mathrm{dBi}$ with side lobe level is $-2.7 \mathrm{~dB}$. Total efficiency antenna is $-1.408 \mathrm{~dB}$. Simulated S-parameters of the arrays are illustrated in Figure 14, the isolations between the consecutive ports, S21, S32, S43 etc., are well below $-20 \mathrm{~dB}$ which show a lesser mutual coupling between them. The performances of the antenna linear array in terms of gain, efficiency, bandwidth, return loss and mutual coefficient are summarized in Table 3.

$88 \mathrm{~mm}$

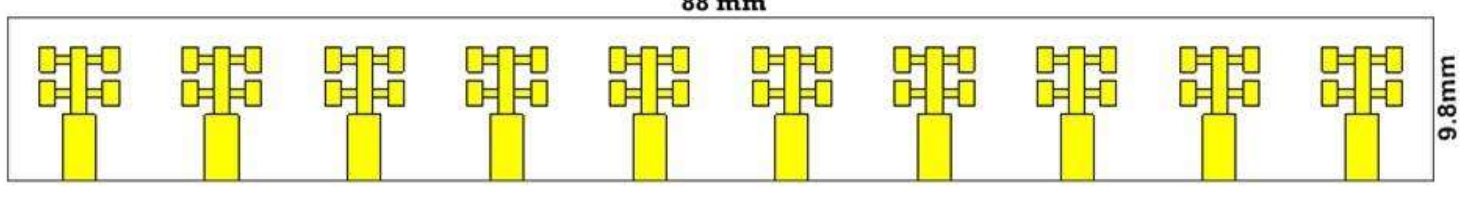

Figure 12. The geometry of ten element MIMO antenna design

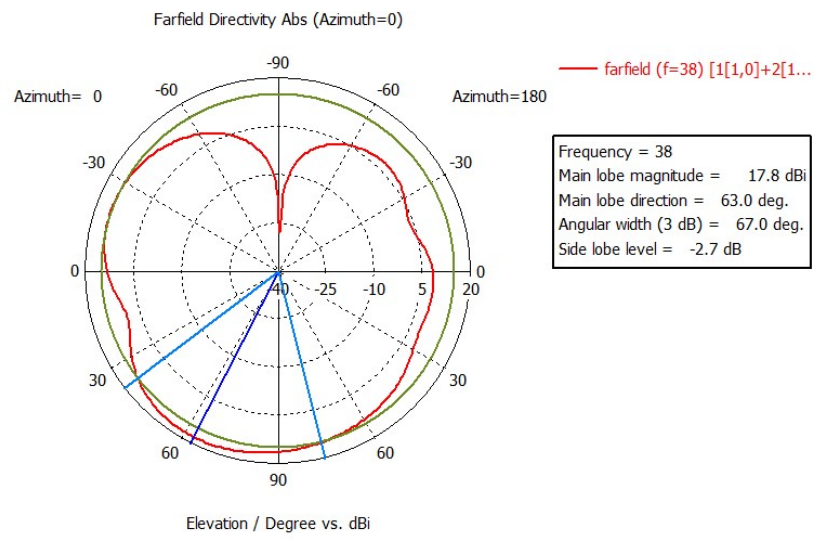

(a)

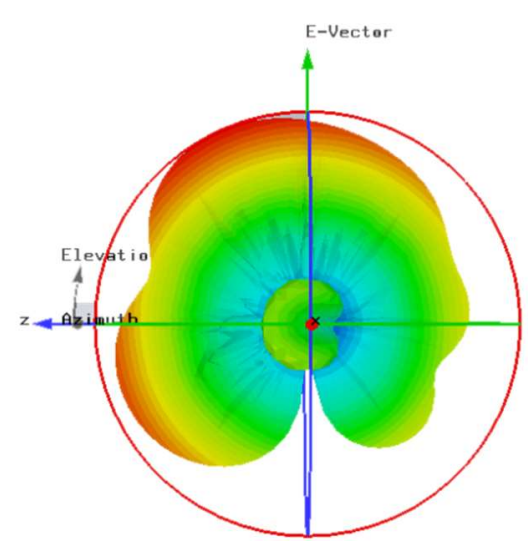

(b)

Figure 13. Radiation pattern of the ten element antenna, (a) 2D model, (b) 3D model 


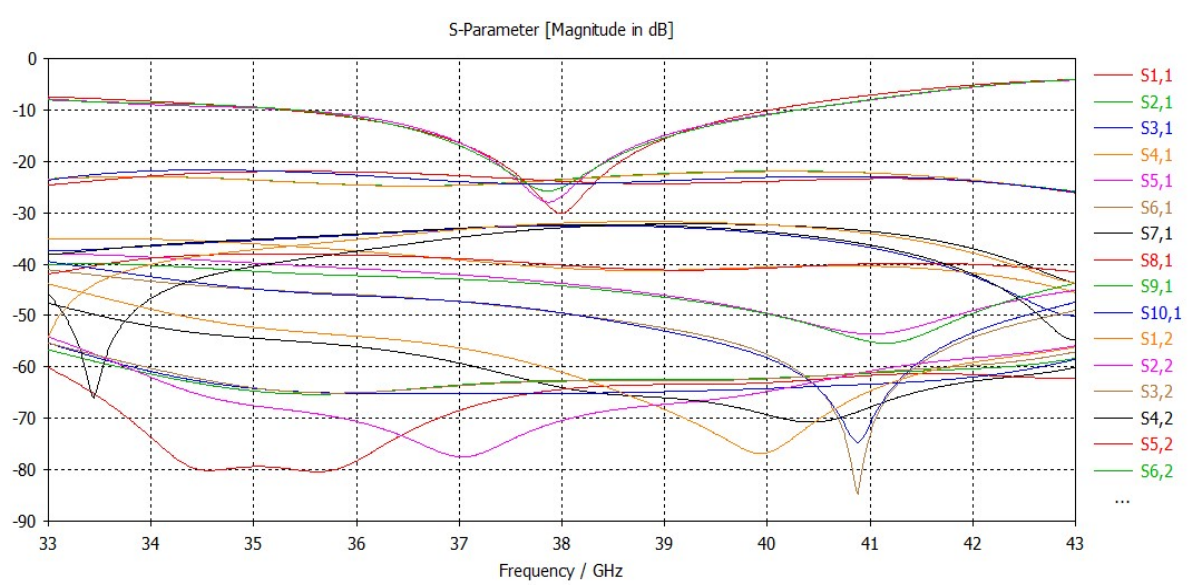

Figure 14. Simulated reflection coefficient $\left(\mathrm{S}_{11}\right)$ characteristics of ten element antenna

Table 3. The Performances of the MIMO Antenna

\begin{tabular}{cccccc}
\hline Variable & Gain & Effic. & BW & Return loss & MC \\
\hline $1 \times 1$ & $7.66 \mathrm{dBi}$ & -0.978 & $4.1 \mathrm{GHz}$ & -59 & - \\
$1 \times 6$ & $15.6 \mathrm{dBi}$ & -1.371 & $4.5 \mathrm{GHz}$ & -30 & $-20 \mathrm{~dB}$ \\
$1 \times 8$ & $16.8 \mathrm{dBi}$ & -1.393 & $4.5 \mathrm{GHz}$ & -30 & $-20 \mathrm{~dB}$ \\
$1 \times 10$ & $17.8 \mathrm{dBi}$ & -1.409 & $4.5 \mathrm{GHz}$ & -30 & $-20 \mathrm{~dB}$ \\
\hline
\end{tabular}

\section{CONCLUSION}

A MIMO antenna which formed by using ten element antenna is designed for $5 \mathrm{G}$ mobile base station that can operate at $38 \mathrm{GHz}$. The antenna was designed on a Rogers Duroid 5880 as subsrate with $1.575 \mathrm{~mm}$-thickness, dielectric constant of $\varepsilon_{-} \mathrm{r}=2,2$ and loss tangent $(\tan \delta)$ of 0,0009 . The simulated results show that the single element antenna has the reflection coefficient (S11) of -59 dB, less than $-10 \mathrm{~dB}$ in the frequency range of $35.5-39.6 \mathrm{GHz}$. More than $4.1 \mathrm{GHz}$ of impedance bandwidth is obtained.

The MIMO antenna covers along the azimuth plane to provide the coverage to the users in omnidirection. When elements were assembled in the form of six element MIMO antenna, there was an increase in antenna gain from $7.66 \mathrm{dBi}$ to $15.6 \mathrm{dBi}$ while the suppression of the side lobes is $-2.8 \mathrm{~dB}$ with efficiency of -1.371 . When elements were assembled in the form of eight element MIMO antenna, there was an increase in antenna gain from $15.6 \mathrm{dBi}$ to $16.8 \mathrm{dBi}$ while the suppression of the side lobes is $-2.7 \mathrm{~dB}$ with efficiency of -1.393 . When elements were assembled in the form of ten element MIMO antenna, there was an increase in antenna gain from $16.8 \mathrm{dBi}$ to $17.8 \mathrm{dBi}$ while the suppression of the side lobes is $-2.7 \mathrm{~dB}$ with efficiency of -1.409 . So we can conclude that there was an increase in antenna gain while addition of each element antenna.

\section{ACKNOWLEDGEMENTS}

The authors would like to thanks to Ministry of Research, Technology and Higher Education of the Republic of Indonesia for their research funding and Wireless Communication Centre (WCC), Universiti Teknologi Malaysia for their support and collaboration.

\section{REFERENCES}

[1] D. N. A. Zaidel et al., "5G Coupler Design or Intelligent Transportation System (ITS) Application," International Journal of Electrical and Computer Engineering (IJECE), vol. 7, no. 2, pp. 899-904, April 2017.

[2] L. C. Yu and M. R. Kamarudin, "5G Fix Beam Switching on Microstrip Patch Antenna," International Journal of Electrical and Computer Engineering (IJECE), vol. 7, no. 2, pp. 975-980, April 2017,

[3] H.Q.Ngo,"Massive MIMO: Fundamentals and System Design," Linkoping Studies in Sciernce and Technology Dissertions, No.1642.

[4] Samsung. (2015, Aug.). Samsung demo: 5G vision, Korea. Available: http://www.samsung.com/global/business/networks/insights/news/samsung-electronics-sets-5g-speedrecord-at-7-5gbpsover-30-times-faster-than-4g-lte. 
[5] G. Gampala and C. J. Reddy, "Design of Millimeter Wave Antenna Arrays for $5 \mathrm{~g}$ cellular Applications Using FEKO," in 2016 IEEEIACES Inter-national Conference on Wireless Information Technology and Systems (ICWITS) and Applied Computational Electromagnetics (ACES), pp. 1-2, 2016.

[6] Y.K. Ningsih and R. Hadinegoro, "Low Mutual Coupling Dualband MIMO Microstrip Antenna Parasitic with Air Gap," TELKOMNIKA, vol. 12, no.2, pp. 405-410, June 2014.

[7] T. Firmansyah et al. "Bandwidth and Gain Enchancement of MIMO Antenna by Using Ring and Circular Parasitic with Air Gap Microstrip Structure,” TELKOMNIKA, vol. 15, no.3, pp. 1155-1163, September 2017.

[8] C.-X. Wang, F. Haider, X. Gao, X.-H. You, Y. Yang, D. Yuan, H. Anggoune, H. Haas, S. Fletcher, and E. Hepsaydir, "Cellular Architecture and Key Technologies for 5G Wireless Communication Network," IEEE Commun. Mag., vol. 52, no. 2, pp. 122-130, Feb. 2014.

[9] T. S. Rappaport, G. R. MacCartney, M. K. Samimi, and S. Sun, "Wide Band Millimeter Wave Propagation Measurements and Channel Models for Future Wireless Communication System Design," IEEE Trans. Commun., vol. 63, no. 9, pp. 3029-3056, Sept. 2015

[10] W. Roh et al., "Millimeter-wave Beamforming as an Enabling Technology for 5G Cellular Communications: Theoretical Feasibility and Prototype Results," IEEE Communications Magazine, vol. 52, pp. 106-113, 2014. no.2, pp.122, 130, February 2014.

[11] F. Rusek, D. Persson, B. Lau, E. Larsson, T. Marzetta, O. Edfors and F. Tufvesson, "Scaling up MIMO: Opportunities and Challenges with Very Large Arrays," IEEE Signal Process. Mag., vol. 30, no. 1, pp. 40-60, Jan. 2013.

[12] E. Larsson, O. Edfors, F. Tufvesson, and T. Marzetta, "Massive Mimo for Next Generation Wireless System," IEEE Commun. Mag., vol. 52, no. 2, pp. 186-195, Feb. 2014.

[13] L. Lu, Y. Li, A. L. Swindlehurst, A. Ashikhmin, and R. Zhang, "An Overview of Massive MIMO: Benefits and Challenges,” IEEE J. Sel. Topics Signal Process., vol.8, no.5, pp 742-758, Oct. 2014.

[14] H. Wei, D.Wang, J. Wang, and X. You, "Impact of RF Mismatches on the Performance of Massive MIMO System with ZF Precoding," Sci. China Inf. Sci., vol. 59, no. 2, pp. 26-39, Feb. 2016.

[15] X. Gao, O. Edfors, F. Rusek, and F. Tufvesson, "Massive MIMO Performance Evaluation based on Measured Propagation Data," IEEE Trans. Wireless Commun., vol. 14, no. 7, pp. 3899-3911, Jul. 2015.

[16] A. L. Swindlehurst, E. Ayanoglu, P. Heydari, and F. Capolino "Millimeter-wave Massive MIMO: The Next Wireless Revolution?" IEEE Commun. Mag., vol. 52, no. 9, pp. 56-62, Sept. 2014.

[17] S.Sur, V. Venkateswaran, X. Zhang, and P. Ramanathan, "60 GHz Indoor Networking Through Flexible Beams: A Link-Level Proviling," in Proc. ACM SIGMETRICS'15, Portland, Oregon, pp. 71-84, Jun. 2015.

[18] X. Wang, S. Mao, and M. X. Gong, "A Survey of LTE wi-fi Coexistence in Unlicensed Bands," GetMobile, vol. 20, no. 3, pp. 17-23, Jul. 2016.

[19] F. Boccardi, R. W. Heath, A. Lozano, T. L. Marzetta, and P. Popovski, "Five Disruptive Technology Direction for 5G," IEEE Commun. Mag., vol. 52, no. 2, pp. 74-80, Feb. 2014.

[20] B. Niboriya, C. Choudhary, and G. Prabhakar, "S-shape Wideband Microstrip Patch Antenna with Enhanced Gain ad Badwidth for Wireless Communication." International Journal of Computer Applications, Vol.73, pp. 17-20, July 2013.

\section{BIOGRAPHIES OF AUTHORS}

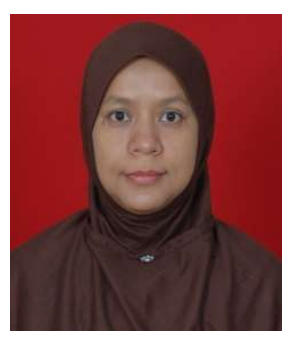

Currently, Yusnita Rahayu is a senior lecturer and a researcher at Faculty of Engineering, Universitas Riau (UR). She has been working for Universitas Riau since 2005 till now. She graduated her B.Eng from Institute Science and Technology National (ISTN), Jakarta in 1999. She finished her PhD from Universiti Teknologi Malaysia (UTM) in 2009 and graduated her Master of Engineering (M.Eng) in 2004 at the same university. She has experiences for more than 10 years in academic and research position at various international and national universities. She has conducted various research projects from national and international grants. Her research interest areas are such as radio transceiver design, antenna design, sensor networks, controlling and monitoring system, IoT and wireless communication system. She has published more than 30 papers for national and international conference, 5 book chapters, 12 international journals. She is also active as reviewer and technical program committee for various journals and conferences. She is a senior member of IEEE and member of IEEE antenna \& propagation society.

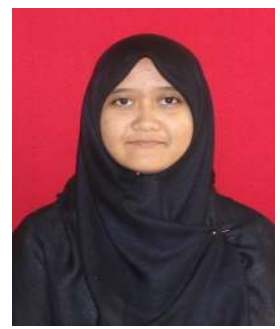

Indah Permata Sari was born in Duri at 1997. She graduated her senior high school at SMAN 1 Mandau. Now, she is a student at Universitas Riau (UR) since 2015 till now in Department of Electrical Engineering. Her interests are antenna design and wireless network. 

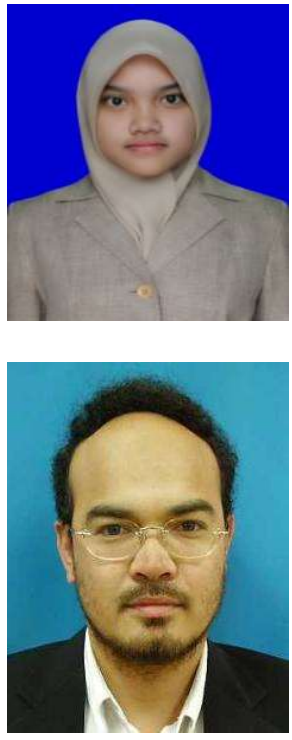

Dara Incam Ramadhan is a student at Universitas Riau (UR) since 2015 till now in Department of Electrical Engineering. She graduated her senior high school at SMAN 4 Duri. Her interests is antenna design.

Assoc. Prof. Dr. Razali Ngah obtained his Bachelor in Electrical Engineering (Communication) from Universiti Teknologi Malaysia, Skudai in 1989, MSc in RF Communication Engineering from University of Bradford, UK in 1996 and $\mathrm{PhD}$ in Photonics from University of Northumbria, UK in 2005. Since 1989, he has been with the Faculty of Electrical Engineering, UTM, where he is currently a Senior Lecturer. Currently, he is an Associate Professor at Wireless Communication Centre (WCC), Faculty of Electrical Engineering, UTM Skudai. His research interests are Mobile Radio Propagation, Antenna and RF design, Photonics Network, Wireless Communication Systems and Radio over Fibre (RoF). Dr. Razali had published more than 50 technical papers for journal and international conferences. His current focus is on his research activity, internal audit committee of university and supervising Postgraduate and Undergraduate students. 